Published in final edited form as:

Int J Gynaecol Obstet. 2009 May ; 105(2): 112-117. doi:10.1016/j.ijgo.2008.12.012.

\title{
Stillbirth and early neonatal mortality in rural Central Africa
}

\author{
Cyril Engmann $^{\mathrm{a}}$, Richard Matendo ${ }^{\mathrm{b}}$, Rinko Kinoshita ${ }^{\mathrm{c}}$, John Ditekemena ${ }^{\mathrm{b}}$, Janet Moore ${ }^{\mathrm{d}}$, \\ Robert L. Goldenberg ${ }^{\mathrm{e}}$, Antoinette Tshefu ${ }^{\mathrm{b}}$, Waldemar A. Carlo ${ }^{f}$, Elizabeth M. McClure ${ }^{\mathrm{d}}$, \\ Carl Bose ${ }^{a}$, and Linda L. Wright ${ }^{9}$ \\ aUniversity of North Carolina at Chapel Hill, North Carolina, USA \\ bKinshasa School of Public Health, Democratic Republic of Congo \\ 'USAID, Kinshasa, Democratic Republic of Congo \\ ${ }^{\mathrm{d}}$ Research Triangle Institute, North Carolina, USA \\ eDrexel University, Philadelphia, USA \\ fUniversity of Alabama at Birmingham, Alabama, USA \\ gNational Institute of Child Health and Development, Bethesda, USA
}

\section{Abstract}

Objective-To develop a prospective perinatal registry that characterizes all deliveries, differentiates between stillbirths and early neonatal deaths (ENDs), and determines the ratio of fresh to macerated stillbirths in the northwest Democratic Republic of Congo.

Method-Birth outcomes were obtained from 4 rural health districts.

Results-A total of 8230 women consented, END rate was 32 deaths per 1000 live births, and stillbirth rate was 33 deaths per 1000 deliveries. The majority (75\%) of ENDs and stillbirths occurred in neonates weighing $1500 \mathrm{~g}$ or more. Odds of stillbirth and END increased in mothers who were single or who did not receive prenatal care, and among premature, low birth weight, or male infants. The ratio of fresh to macerated stillbirths was $4: 1$.

Conclusion-Neonates weighing $1500 \mathrm{~g}$ or more at birth represent a group with a high likelihood of survival in remote areas, making them potentially amenable to targeted intervention packages. The ratio of fresh to macerated stillbirths was approximately 10 -fold higher than expected, suggesting a more prominent role for improved intrapartum obstetric interventions.

\section{Keywords}

Africa; Early neonatal death; Fresh and macerated stillbirth; Low-income country

\footnotetext{
(c) 2009 International Federation of Gynecology and Obstetrics. Published by Elsevier Ireland Ltd. All rights reserved.

Corresponding Author: Cyril Engmann, Division of Neonatal-Perinatal Medicine, Department of Pediatrics, University of North Carolina School of Medicine, CB\#7596, 4th Floor, UNC Hospitals, UNC-Chapel Hill, Chapel Hill, NC 27599-7596. cengmann@med.unc.edu.

Publisher's Disclaimer: This is a PDF file of an unedited manuscript that has been accepted for publication. As a service to our customers we are providing this early version of the manuscript. The manuscript will undergo copyediting, typesetting, and review of the resulting proof before it is published in its final citable form. Please note that during the production process errors may be discovered which could affect the content, and all legal disclaimers that apply to the journal pertain.
} 


\section{Introduction}

Each year, 7 million neonates are stillborn or die within the first 7 days of life [1,2]. Over $98 \%$ of these stillbirths and early neonatal deaths (perinatal deaths) occur in low-income countries, and regional estimates suggest that countries in Sub-Saharan Africa have among the highest perinatal mortality rates in the world $[3,4]$. Such countries with disproportionately high perinatal mortality rates often have weak health metrics and systems, resulting in a paucity of perinatal morbidity and mortality information [5, 6] and a deficiency in quality of available data [7]. At present, data used to estimate perinatal mortality in many low-income countries are derived from complex, statistical modeling techniques or from nationally representative demographic and health surveys which use cluster-sampling of live births, thus providing neonatal mortality rates, but little information on stillbirths and their surrounding circumstances [8]. Other studies of perinatal deaths have been conducted in hospitals with relatively small sample sizes, limiting their generalizability $[9,10]$. Few accurate registries document perinatal outcomes in a community setting. This is of particular importance because current estimates suggest that over two-thirds of perinatal deaths occur at home and may not be included in vital registration or health facility data [11]. This dearth of accurate, population-based, perinatal data poses significant challenges to developing a coherent, perinatal health policy in Sub-Saharan Africa.

The objective of the present study was to develop a prospective perinatal registry that characterized all deliveries and perinatal deaths, differentiated between stillbirths and early neonatal deaths (ENDs), and determined the ratio of fresh to macerated stillbirths in a remote, rural area in the Democratic Republic of Congo (DRC). Based on World Health Organization (WHO) regional perinatal estimates [4], we hypothesized that the stillbirth to END rate ratio would be 1.3:1 and the ratio of fresh to macerated stillbirths would be 1:2.

\section{Materials and methods}

The DRC spans 2.3 million $\mathrm{km}^{2}$ and has an estimated population of 66 million. The study was conducted in 4 health districts of the Equateur Province, in northwest DRC. This region, which has little electricity, few health facilities, and many transportation challenges, is representative of rural DRC.

This prospective observational study was nested within an ongoing, cluster-randomized control trial, the FIRST BREATH Trial, conducted by the Global Network (GN) for Women and Children's Health. The GN is a multicountry research network funded by the National Institutes of Health, representing partnerships of US and international investigators. The FIRST BREATH Trial is investigating the benefits of implementing a package of neonatal care practices and a neonatal resuscitation training program in community settings. As part of this study, birth attendants were trained to collect basic maternal, fetal, and neonatal outcome data which included demographics, mode of delivery, birth weight, gestational age, need for resuscitation, and details of adverse events. They received knowledge and skills training in newborn care using the WHO Essential Newborn Care (ENC) program. The data for the present study were collected during the baseline and ENC phases of the FIRST BREATH Trial. Table 1 outlines the operational definitions used in the study.

Within the 4 health districts, 12 communities participated in the study. Pregnant women were enrolled at the first prenatal visit, which was usually by 24 weeks of pregnancy. Trained nurses appointed as Community Coordinators oversaw data collection by all birth attendants in the community. Delivery locations included hospitals, health centers, home (including the birth attendants' home), or other (in transit). After each delivery, Community Coordinators collected data recorded by birth attendants. Oversight for Community Coordinators was by a physician Provincial Coordinator. Data collection was the 
responsibility of birth attendants. Illiterate birth attendants were accompanied by literate community scribes who assisted with documentation. Training utilized the train-the-trainer model outlined in a previous GN publication [12]. All birth attendants were trained to check for fetal and neonatal vital signs in every baby by auscultating the abdomen of each pregnant woman before delivery, and after delivery by feeling the neonate's umbilical cord for a pulse, auscultating lungs for breath sounds, and assessing for any movement. Birth weights were obtained within 48 hours of delivery using Salter spring scales (UNICEF model 145555) provided for the study.

Data were collected between June 2005 and January 2007, and were entered into an electronic database in Equateur, and then sent by courier to Kinshasa where data edits, including inter- and intra-form consistency checks were performed. Data were then transmitted to the Data Coordination Center (Research Triangle Institute, Research Triangle Park, NC, USA). The study was reviewed and approved by the institutional ethics review committees of the Kinshasa School of Public Health, University of North Carolina, and Research Triangle Institute. Verbal informed consent was obtained from the participants at the time of enrollment.

The data were analyzed using SAS version 9.1.3 (SAS Institute Inc, Cary, NC, USA). Descriptive analyses were conducted to describe delivery location, level of training of birth attendants, maternal characteristics, and neonatal characteristics. Factors potentially associated with perinatal mortality rates were grouped into obstetric and sociodemographic maternal characteristics, type of birth attendant, delivery location, and neonatal characteristics. Unadjusted odds ratios were computed to asses the relationship between outcomes (stillbirth, early neonatal deaths, and perinatal mortality) and selected variables. Reference categories were defined as those usually associated with the lowest stillbirth and END rates. Because the data were from a cluster intervention study, the $95 \%$ confidence intervals were adjusted to account for the inter-cluster correlation. All variables found to be significantly associated with perinatal deaths, stillbirths, and ENDs were then included in a Generalized Estimation Equation model which adjusted for the correlated observations within a cluster, and odds ratios and $95 \%$ confidence intervals adjusted for cluster data were obtained.

\section{Results}

Of 8257 women who were screened, 8230 (99.7\%) consented and were subsequently enrolled, and 7940 (99.8\%) completed the 7-day follow-up visit (Fig. 1). Most (95\%) of the women had at least 1 prenatal care visit (data not shown). Table 2 shows that $74 \%$ of deliveries occurred at the home of a traditional birth attendant (TBA) or the mother, 25\% occurred in clinics or health centers, and less than $1 \%$ occurred in hospitals. Almost all deliveries (98\%) were by the vaginal route, with the majority (78\%) attended by non-skilled birth attendants (TBA or family). Skilled birth attendants (SBAs) were present at $21 \%$ of deliveries. The majority (97\%) of births were singleton deliveries. The mean birth weight among neonates delivered during the study period was $3044 \pm 570 \mathrm{~g} ; 12 \%$ of neonates were low birth weight $(<2500 \mathrm{~g})$, and $1.5 \%$ were very low birth weight $(<1500 \mathrm{~g})$.

Table 3 shows that the perinatal mortality rate was 64 deaths per 1000 deliveries. In univariate analysis the following maternal factors increased the odds for perinatal death: single status, lack of prenatal care, and no formal education. Neonatal characteristics that increased the odds of death included male sex, prematurity, multiple birth, and low birth weight. 
In multivariate analysis, very low birth weight and prematurity increased the odds of perinatal death nearly 20 -fold. The odds for perinatal death were tripled if the mother was single and nearly doubled if she had no prenatal care or gave birth to a male child.

Table 4 shows that there were 271 stillbirths resulting in a stillbirth rate of 33 per 1000 deliveries. Nearly half $(46 \%)$ of stillbirths occurred in neonates with birth weights greater than $2500 \mathrm{~g}$; almost one-third (29\%) and a quarter (25\%) of stillbirths occurred in neonates weighing 1500-2499 g and less than $1500 \mathrm{~g}$, respectively. Within birth weight categories, $53 \%$ of neonates weighing between 500 and $1499 \mathrm{~g}$ were stillborn, $9 \%$ weighing between 1500 and $2499 \mathrm{~g}$ were stillborn, and $2 \%$ weighing more than $2500 \mathrm{~g}$ were stillborn.

In multivariate analysis, very low birth weight neonates had 9 times the odds of stillbirth while prematurity increased the odds nearly 8 -fold. Lack of prenatal care and birth weight between 1500 and $2499 \mathrm{~g}$ doubled the odds of stillbirth.

Table 5 shows that $79 \%$ (214) of stillbirths were fresh and 21\% (57) were macerated. Lack of prenatal care and single status tended to increase the risk of fresh versus macerated stillbirth, as did no formal education, delivery by a TBA, delivery in the home, and prematurity; however, none of the variables were statistically significant.

Table 6 shows the END rate was 32 deaths per 1000 live births. Forty-seven percent of ENDs occurred in neonates weighing $2500 \mathrm{~g}$ or more and $34 \%$ of ENDs were in low birth weight neonates weighing between 1500 and $2499 \mathrm{~g}$. When ENDs were considered within each birth weight category, $76 \%$ of neonates weighing between 500 and $1499 \mathrm{~g}$ died, $11 \%$ weighing between 1500 and $2499 \mathrm{~g}$ died, and $1.7 \%$ weighing greater than $2500 \mathrm{~g}$ died. Results from univariate and multivariate analysis for END paralleled those for stillbirth: there was a more than 20-fold increased odds of END in premature neonates and a 10-fold increase in neonates with birth weights between 500 and $1499 \mathrm{~g}$. Similarly, odds of END were doubled if neonates weighed $1500-2499 \mathrm{~g}$ or if their mothers had no prenatal care.

\section{Discussion}

The overall stillbirth rate of 33 per 1000 births and END rate of 32 per 1000 live births represent a more than 7-fold higher rate than is reported for high-income countries [13]. The END rate is similar to WHO modeled estimates (35 per 1000 live births), although the stillbirth rate is considerably lower than WHO modeled estimates (42 per 1000 births) [14]. One explanation for this difference may be less misclassification of END as stillbirth in our cohort. Stillbirth and END may be misclassified for various reasons including lack of knowledge or information to distinguish the two, lack of careful assessment of signs of life, avoidance of blame, extra work or audit review for the birth attendant, or perceived gain or loss for the family [15]. Often, routine auscultation or palpation of the umbilical cord for signs of a heart rate does not accompany every delivery, and breathing efforts of a neonate may be very subtle making it easy for birth attendants to conclude that a neonate in secondary apnea is stillborn [15]. It is likely that the rigorous training of TBAs in our study decreased misclassification. The stillbirth to END ratio was $1: 1$, which is in contrast to many published estimates that report ratios of 1.3:1. This more accurate estimate of the contribution of stillbirth to the total burden of perinatal mortality may be important for developing programmatic interventions in rural remote areas where stillbirth rates are unobtainable.

Prematurity and low birth weight conferred the highest odds of perinatal death, with a 20fold increased odds if neonates were premature or very low birth weight. Birth weight is an important proxy for viability, especially where reliable gestational age dating is not available. Most studies of perinatal mortality in low-income countries have not included 
birth weight; when they have, a cut-off value of $1000 \mathrm{~g}$ has generally been used to define viability [16]. In the present study, a cut-off value of $500 \mathrm{~g}$, used by many high-income countries, was utilized. When compared by birth weight categories, stillbirths and ENDs had strikingly similar proportions. Nearly half of the perinatal deaths occurred in neonates weighing $2500 \mathrm{~g}$ or more, with three-quarters occurring in neonates weighing $1500 \mathrm{~g}$ or more. Among neonates weighing $1500 \mathrm{~g}$ or more, survival in rural, remote areas is possible [17] with targeted intervention packages such as maternal tetanus immunization, clean cord practices, exclusive breast feeding, skin-to-skin (kangaroo) care, and recognition and early treatment of infection $[11,18,19]$.

The risk of perinatal death was increased 2-fold if mothers had not received prenatal care. Most women (95\%) in our cohort received at least one prenatal care visit. In high-income country settings, maternal age, educational level, and income, as well as ethnicity, marital status, physical violence in the home, desire for pregnancy, and insurance coverage have been found to influence the adequacy of prenatal care [20]. Less is known about the antecedents of inadequate prenatal care in rural, resource-constrained African settings. Paredes et al. [21] reported in a study conducted among a poor population in Central America, that 5 major factors adversely influenced prenatal care utilization: economic difficulties; the need to care for a young child; transportation difficulties; long waiting lines to access healthcare; and an overall lack of knowledge.

A surprising finding was that the ratio of fresh to macerated stillbirths was nearly $4: 1$. Fresh stillbirths are used as a proxy for stillbirths due to acute intrapartum insults [16]. Lawn et al. [1] estimated intrapartum stillbirth using data from 52 countries with a cumulative sample size of 46779 stillbirths. In their model they estimated there were 1.02 million intrapartum (fresh) stillbirths out of a total of 3.9 million, resulting in a ratio of fresh to macerated stillbirths of 1:3. Similar ratios have been noted in the literature [22, 23]. Lawn et al. [1] noted wide disparities in intrapartum stillbirth rates when comparing regions with the highest and lowest rates. Countries in the Western Pacific, northwest Europe, and North Americas had intrapartum stillbirth rates of less than 1 per 1000 total births, while countries in Sub-Saharan Africa and South East Asia had rates 15 times higher. There was a 50-fold difference when they compared the lowest ( 0.33 per 1000 total deaths) and highest (17.4 per 1000 total births) reported stillbirth rates. Goldenberg et al. [24] compared the ratio of intrapartum to antepartum stillbirth in low- and high-income countries using Lawn's estimations of intrapartum deaths and overall stillbirth estimates from Stanton et al. [15]. They found a ratio of intrapartum to antepartum stillbirth of nearly 1:5 for high-income countries and 1:2 for low-income countries. The ratios of fresh to macerated stillbirths may reflect the quality of prenatal and obstetric care, with high ratios implying poorer care [22]. Supporting this, Goldenberg et al. [24] assessed the relationship between provision of emergency obstetric services using cesarean deliveries as proxy values, and intrapartum and antepartum stillbirths. They depicted a linear relationship on a scatterplot of intrapartum (fresh) stillbirths and provision of obstetric services, when compared with that of antepartum stillbirths and provision of obstetric services. Furthermore, there was a dramatic decrease in intrapartum stillbirth rates when cesarean delivery rates increased from $0-10 \%$.

The relatively high ratio of fresh to macerated stillbirths from our data is contrary to the above reports. McClure et al. [16] reported on the outcome of 60324 pregnancies resulting in 1472 stillbirths in 5 low-income countries and 1 middle-income country, and found ratios of fresh to macerated stillbirths of nearly $5: 1$, which is consistent with our data. The public health ramification of higher fresh to macerated stillbirth ratios is that fresh stillbirths are amenable to interventions that are likely to result in improved outcomes [25]. 
As with any descriptive epidemiologic study, cause and effect cannot be discerned from the data. Nonetheless, the increased odds of death due to infant factors such as prematurity, low birth weight and male sex, and maternal factors such as no prenatal care, no education, and single status begin to explore which modifiable factors contribute to perinatal deaths in rural Central Africa. The present study was designed to provide population data and therefore lacks an adequate comparison group. Additionally, the categorization used for maternal age may have masked the effect of teenage pregnancy. Major strengths of this study are the large sample size, high consent and 7-day follow-up rate, extent of data validation and study oversight provided by Community Coordinators, and the collection of stillbirth weight, often a difficult task because of cultural and other barriers [15].

In conclusion, stillbirths and early neonatal deaths remain significant problems in lowincome countries. Neonates weighing $1500 \mathrm{~g}$ or more represent a group with a high likelihood of survival in remote areas, making them potentially amenable to targeted intervention packages. The ratio of fresh to macerated stillbirths was approximately 10 -fold higher than expected, suggesting a more prominent role for improved intrapartum obstetric interventions.

\section{Acknowledgments}

Funding was provided by grants from the National Institute of Child Health and Human Development (U01 HD043475) and the Bill and Melinda Gates Foundation.

\section{References}

1. Lawn J, Shibuya K, Stein C. No cry at birth: global estimates of intrapartum stillbirths and intrapartum-related neonatal deaths. Bull World Health Organ. 2005; 83(6):409-17. [PubMed: 15976891]

2. Lawn JE, Cousens S, Zupan J. 4 million neonatal deaths: when? Where? Why? Lancet. 2005; 365(9462):891-900. [PubMed: 15752534]

3. Lopez AD, Mathers CD, Ezzati M, Jamison DT, Murray CJ. Global and regional burden of disease and risk factors, 2001: systematic analysis of population health data. Lancet. 2006; 367(9524): 1747-57. [PubMed: 16731270]

4. World Health Organization. World Health Report - Make Every Mother and Child Count. Geneva: WHO; 2005.

5. Setel PW, Sankoh O, Rao C, Velkoff VA, Mathers C, Gonghuan Y, et al. Sample registration of vital events with verbal autopsy: a renewed commitment to measuring and monitoring vital statistics. Bull World Health Organ. 2005; 83(8):611-7. [PubMed: 16184280]

6. Rao C, Lopez AD, Yang G, Begg S, Ma J. Evaluating national cause-of-death statistics: principles and application to the case of China. Bull World Health Organ. 2005; 83(8):618-25. [PubMed: 16184281]

7. Bhutta ZA. The Million Death Study in India: can it help in monitoring the millennium development goals? PLoS Med. 2006; 3(2):e103. [PubMed: 16464134]

8. Adazu K, Lindblade KA, Rosen DH, Odhiambo F, Ofware P, Kwach J, et al. Health and Demographic Surveillance in Rural Western Kenya: A Platform for Evaluating Interventions to Reduce Morbidity and Mortality from Infectious Diseases. Am J Trop Med Hyg. 2005; 73(6):11511158. [PubMed: 16354829]

9. Morbidity and mortality among outborn neonates at 10 tertiary care institutions in India during the year 2000. J Trop Pediatr. 2004; 50(3):170-4. [PubMed: 15233194]

10. Kunzel W, Herrero J, Onwuhafua P, Staub T, Hornung C. Maternal and perinatal health in Mali, Togo and Nigeria. Eur J Obstet Gynecol Reprod Biol. 1996; 69(1):11-7. [PubMed: 8909951]

11. Bhutta ZA, Darmstadt GL, Hasan BS, Haws RA. Community-based interventions for improving perinatal and neonatal health outcomes in developing countries: a review of the evidence. Pediatrics. 2005; 115(2 Suppl):519-617. [PubMed: 15866863] 
12. McClure EM, Carlo WA, Wright LL, Chomba E, Uxa F, Lincetto O, et al. Evaluation of the educational impact of the WHO Essential Newborn Care course in Zambia. Acta Paediatr. 2007; 96(8):1135-8. [PubMed: 17608829]

13. Goldenberg RL, Kirby R, Culhane JF. Stillbirth: a review. J Matern Fetal Neonatal Med. 2004; 16(2):79-94. [PubMed: 15512717]

14. World Health Organization. Neonatal and perinatal mortality: Country, regional and global estimates. Genea: WHO; 2006. Available at: http://www.who.int/reproductive-health/docs/ neonatal_perinatal_mortality/text.pdf [Accessed December 8, 2008]

15. Stanton C, Lawn JE, Rahman H, Wilczynska-Ketende K, Hill K. Stillbirth rates: delivering estimates in 190 countries. Lancet. 2006; 367(9521):1487-94. [PubMed: 16679161]

16. McClure EM, Wright LL, Goldenberg RL, Goudar S, Parida S, Jehan A, et al. The global network: a prospective study of stillbirths in developing countries. Am J Obstet Gynecol. 2007; 197(3):247, e1-5. [PubMed: 17826406]

17. van der Mei J, Volmer M, Boersma ER. Growth and survival of low birthweight infants from 0 to 9 years in a rural area of Ghana. Comparison of moderately low (1,501-2,000 g) and very low birthweight (1,000-1,500 g) infants and a local reference population. Trop Med Int Health. 2000; 5(8):571-7. [PubMed: 10995099]

18. Haws RA, Thomas AL, Bhutta ZA, Darmstadt GL. Impact of packaged interventions on neonatal health: a review of the evidence. Health Policy Plan. 2007; 22(4):193-215. [PubMed: 17526641]

19. Darmstadt GL, Bhutta ZA, Cousens S, Adam T, Walker N, de Bernis L. Evidence-based, costeffective interventions: how many newborn babies can we save? Lancet. 2005; 365(9463):977-88. [PubMed: 15767001]

20. Kotelchuck M. Adequacy of prenatal care utilization. Epidemiology. 1997; 8(5):602-4. [PubMed: 9270968]

21. Paredes I, Hidalgo L, Chedraui P, Palma J, Eugenio J. Factors associated with inadequate prenatal care in Ecuadorian women. Int J Gynecol Obstet. 2005; 88(2):168-72.

22. Feresu SA, Harlow SD, Welch K, Gillespie BW. Incidence of stillbirth and perinatal mortality and their associated factors among women delivering at Harare Maternity Hospital, Zimbabwe: a cross-sectional retrospective analysis. BMC Pregnancy Childbirth. 2005; 5(1):9. [PubMed: 15876345]

23. Amar HS, Maimunah AH, Wong SL. Use of Wigglesworth pathophysiological classification for perinatal mortality in Malaysia. Arch Dis Child Fetal Neonatal Ed. 1996; 74(1):F56-9. [PubMed: 8653438]

24. Goldenberg RL, McClure EM, Bann CM. The relationship of intrapartum and antepartum stillbirth rates to measures of obstetric care in developed and developing countries. Acta Obstet Gynecol Scand. 2007; 86(11):1303-9. [PubMed: 17963057]

25. Jehan I, McClure EM, Salat S, Rizvi S, Pasha O, Harris H, et al. Stillbirths in an urban community in Pakistan. Am J Obstet Gynecol. 2007; 197(3):257, e1-8. [PubMed: 17826410] 


\section{Synopsis}

The early neonatal death rate was 32 per 1000 live births and the stillbirth rate was 33 per 1000 deliveries. The ratio of fresh to macerated stillbirths was 4:1, approximately 10 -fold higher than expected. 


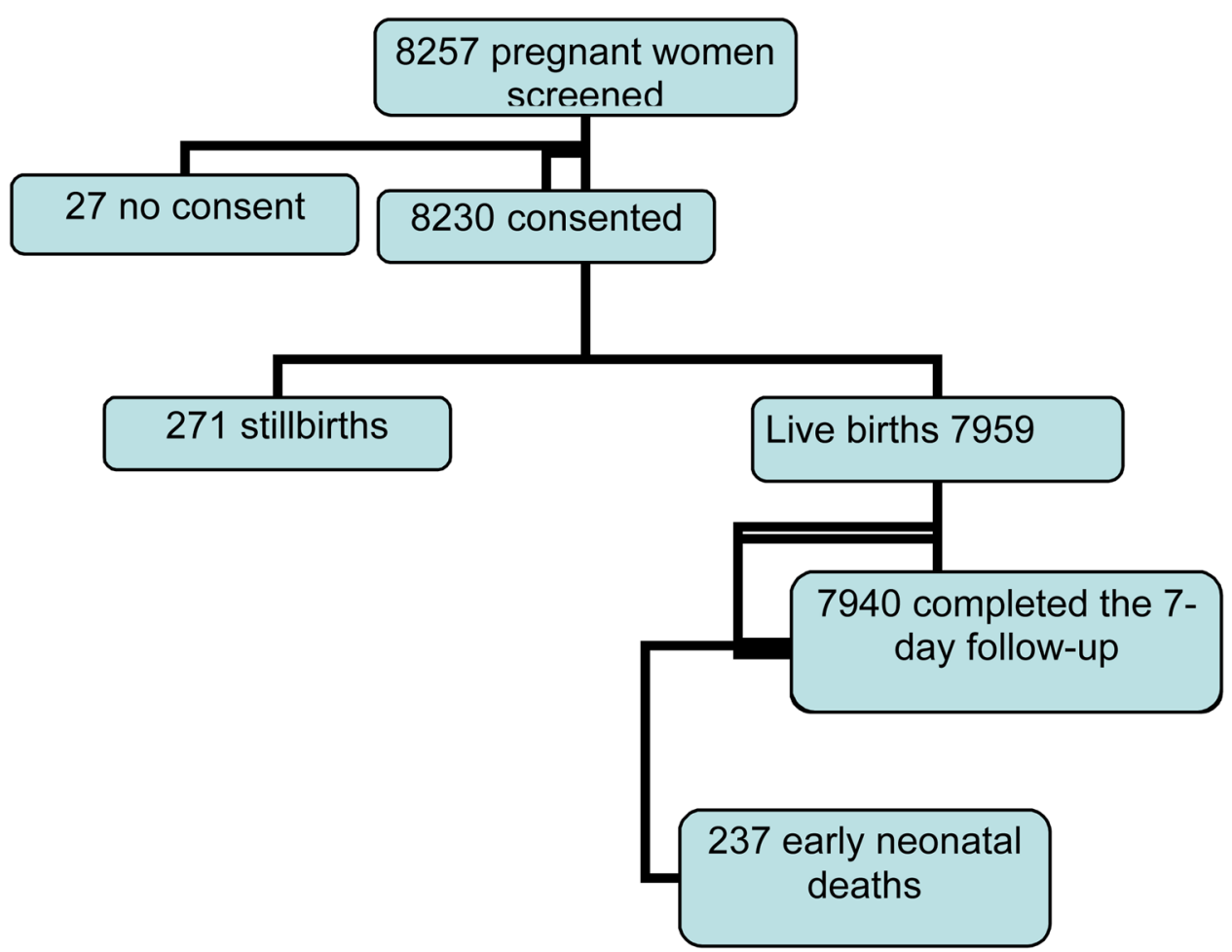

Figure 1.

Study population 
Table 1

Operational definitions used for the study

- Early neonatal death rate: death of a live born infant at or before 7 days of life per 1000 live deliveries.

- Stillbirth rate: fetal loss $\geq 500 \mathrm{~g}$ birth weight or corresponding to approximately 24 weeks of gestation or more per 1000 deliveries, with no signs of life at birth, i.e. no breathing, no heart rate, and no movement.

- Perinatal mortality rate: the sum of the early neonatal death and stillbirth rates.

- Fresh or intrapartum stillbirth: a neonate born dead within 12-24 hours of delivery, without signs of skin disintegration.

- $\quad$ Macerated stillbirth: A stillbirth with pulpy peeling skin suggesting death occurred more than 12-24 prior to delivery.

- $\quad$ Prematurity: Birth before 37 completed weeks of pregnancy.

- Low birth weight neonate: A neonate weighing less than $2500 \mathrm{~g}$ at birth.

- Very low birth weight neonate: A neonate weighing less than $1500 \mathrm{~g}$ at birth

- Gestational age: The duration of pregnancy; determined using the mothers last menstrual period.

- $\quad$ Traditional birth attendant (TBA): A person who assists other women during childbirth and initially acquired her skills by delivering babies or through apprenticeship to other TBAs.

- $\quad$ Trained TBA: A TBA who has successfully completed a short period of instruction in the management of childbirth, i.e. was certified.

- Untrained TBA: A TBA with no government or other training.

- $\quad$ Skilled birth attendant (SBA): A nurse, midwife, or doctor who provided obstetric care

- $\quad$ Prenatal care: At least one visit with a skilled birth attendant.

- Community: A distinct geographic region whose birth attendants did not overlap with other communities. Each community comprised of a cluster of smaller villages with approximately 300 annual deliveries. 


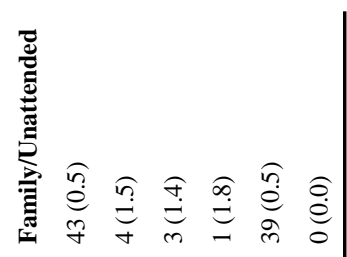

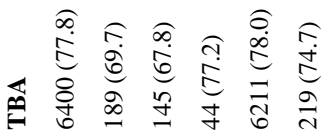

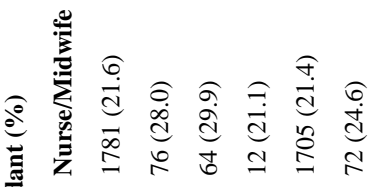$$
\text { 产 }
$$

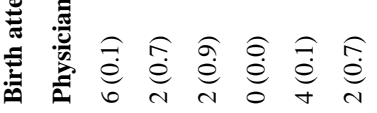

इ

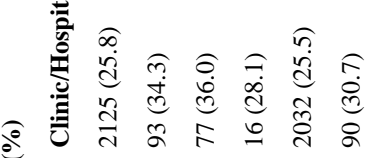
ฮ.

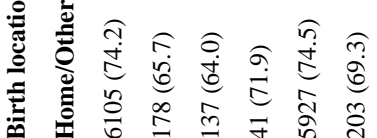


Table 3

Characteristics by mother, perinatal care, neonates, and associated perinatal mortality

\begin{tabular}{|c|c|c|c|c|}
\hline Categories & Total deliveries (\%total) & $\begin{array}{l}\text { Total perinatal deaths } \\
\text { (perinatal mortality rate) }\end{array}$ & Odds ratio $(95 \%$ CI) & $\begin{array}{l}\text { GEE model } \\
\text { Odds ratio }(95 \% \mathrm{CI})\end{array}$ \\
\hline \multicolumn{5}{|l|}{ Maternal characteristics } \\
\hline Maternal age, y & 8230 & & & \\
\hline$<25$ & $4043(49.1)$ & $265(65.5)$ & 1.0 & \\
\hline $25-35^{\mathrm{a}}$ & $3002(36.5)$ & $182(60.6)$ & $0.92(0.70-1.22)$ & \\
\hline$>35$ & $1185(14.4)$ & $79(66.7)$ & $1.02(0.70-1.48)$ & \\
\hline Educational status & 8230 & & & \\
\hline No formal education & $5,263(63.9)$ & $375(71.3)$ & $1.43(1.08-1.89)$ & $1.32(1.01-1.73)$ \\
\hline Any formal education ${ }^{a}$ & $2,967(36.1)$ & $151(50.9)$ & 1.0 & 1.0 \\
\hline Presence of partner & 8230 & & & \\
\hline Single & $90(1.1)$ & $16(177.8)$ & $3.23(1.48-7.08)$ & $3.35(1.67-6.72)$ \\
\hline Married/cohabiting & $8140(98.9)$ & $510(62.7)$ & 1.0 & 1.0 \\
\hline Parity & 8230 & & & \\
\hline 0 & $1842(22.4)$ & $142(77.1)$ & $1.32(0.97-1.79)$ & \\
\hline $1-3^{\mathrm{a}}$ & $4020(48.8)$ & $240(59.7)$ & 1.0 & \\
\hline$>3$ & $2368(28.8)$ & $144(60.8)$ & $1.02(0.75-1.38)$ & \\
\hline Number of children & 8230 & & & \\
\hline 0 & $2352(28.6)$ & $201(85.5)$ & $1.55(1.18-2.05)$ & NS \\
\hline $1-3^{a}$ & $4321(52.5)$ & $245(56.7)$ & 1.0 & \\
\hline$>3$ & $1557(18.9)$ & $80(51.4)$ & $0.90(0.62-1.31)$ & \\
\hline Prenatal care & 8230 & & & \\
\hline No prenatal care & $388(4.7)$ & $57(146.9)$ & $2.71(1.77-4.13)$ & $1.89(1.40-2.56)$ \\
\hline One visit or more ${ }^{a}$ & $7842(95.3)$ & $469(59.8)$ & 1.0 & 1.0 \\
\hline Birth attendant & 8230 & & & \\
\hline Physician ${ }^{\text {a }}$ & $6(0.1)$ & $2(33.3)$ & 1.0 & \\
\hline Nurse/midwife & 1781 (21.6) & $150(84.2)$ & $0.18(0.02-2.11)$ & \\
\hline TBA/family/unattended & $6443(78.3)$ & $374(58.0)$ & $0.12(0.01-1.40)$ & \\
\hline Delivery location & 8230 & & & \\
\hline Home/other & $6105(74.2)$ & $347(56.8)$ & $0.66(0.50-0.86)$ & NS \\
\hline Clinic/hospital ${ }^{\text {a }}$ & 2125 (25.8) & $179(84.2)$ & 1.0 & \\
\hline \multicolumn{5}{|l|}{ Infant characteristics } \\
\hline Sex & 8213 & & & \\
\hline Male & $4260(51.9)$ & $307(72.1)$ & $1.33(1.03-1.72)$ & $1.69(1.21-2.37)$ \\
\hline Female $^{\text {a }}$ & $3953(48.1)$ & $218(55.1)$ & 1.0 & 1.0 \\
\hline Gestational age, wk & 8213 & & & \\
\hline$<37$ weeks & $302(3.7)$ & $223(738.4)$ & $71.12(47.57-106.33)$ & $19.55(10.27-37.23)$ \\
\hline$>37$ weeks $^{\text {a }}$ & $7911(96.3)$ & $302(38.2)$ & 1.0 & 1.0 \\
\hline Birth weight, $g$ & 8192 & & & \\
\hline $500-1499$ & $124(1.5)$ & $110(887.1)$ & $229.57(101.47-519.36)$ & $20.29(9.20-44.75)$ \\
\hline
\end{tabular}




\begin{tabular}{cllll}
\hline Categories & Total deliveries (\%total) & $\begin{array}{l}\text { Total perinatal deaths } \\
\text { (perinatal mortality rate) }\end{array}$ & Odds ratio (95\% CI) & $\begin{array}{l}\text { GEE model } \\
\text { Odds ratio (95\% CI) }\end{array}$ \\
$1500-2499$ & $846(10.3)$ & $161(190.3)$ & $6.87(5.05-9.33)$ & $2.85(1.85-4.41)$ \\
2500 & $7222(88.2)$ & $239(33.1)$ & 1.0 & 1.0 \\
Multiple births & 8230 & & & NS \\
Yes & $293(3.6)$ & $52(177.5)$ & $3.40(2.17-5.32)$ & \\
No & $7937(96.4)$ & $474(59.7)$ & 1.0 & \\
\hline
\end{tabular}

Abbreviations: NS, not significant; GEE, generalized estimation model. 
Table 4

Characteristics by other, perinatal care, neonates, and associated stillbirth

\begin{tabular}{|c|c|c|c|c|}
\hline Categories & Total deliveries (\% Total) & $\begin{array}{r}\text { Total number of stillbirths } \\
\text { (stillbirth rate) }\end{array}$ & Odds ratio (95\% CI) & $\begin{array}{r}\text { GEE model } \\
\text { Odds ratio }(95 \% \mathrm{CI})\end{array}$ \\
\hline \multicolumn{5}{|l|}{ Maternal characteristics } \\
\hline Maternal age, y & 8230 & & & \\
\hline$<25$ & $4043(49.1)$ & $137(33.9)$ & 1.0 & \\
\hline $25-35$ a & $3002(36.5)$ & 95 (31.6) & $0.93(0.47-1.84)$ & \\
\hline$>35$ & $1185(14.4)$ & $39(32.9)$ & $0.97(0.38-2.45)$ & \\
\hline Education status & 8230 & & & \\
\hline No formal education & $5263(63.9)$ & $196(37.2)$ & $1.49(0.75-2.98)$ & \\
\hline Any formal education a & $2967(36.1)$ & $75(25.3)$ & 1.0 & \\
\hline Presence of partner & 8230 & & & \\
\hline Single & $90(1.1)$ & $9(100.0)$ & $3.34(0.56-20.01)$ & \\
\hline Married/cohabiting & $8140(98.9)$ & $262(32.2)$ & 1.0 & \\
\hline Parity & 8230 & 271 & & \\
\hline 0 & $1842(22.4)$ & $69(37.5)$ & $1.32(0.61-2.87)$ & \\
\hline $1-3^{a}$ & $4020(48.8)$ & $115(28.6)$ & 1.0 & \\
\hline$>3$ & $2368(28.8)$ & $87(36.7)$ & $1.30(0.63-2.67)$ & \\
\hline Number of children & 8230 & 271 & & \\
\hline 0 & $2352(28.6)$ & $101(42.9)$ & $1.57(0.79-3.13)$ & \\
\hline $1-3^{\text {a }}$ & $4321(52.5)$ & $120(27.8)$ & 1.0 & \\
\hline$>3$ & 1557 (18.9) & $50(32.1)$ & $1.16(0.49-2.74)$ & \\
\hline Prenatal care & 8230 & & & \\
\hline No prenatal care & $388(4.7)$ & $33(85.1)$ & $2.97(1.13-7.84)$ & $1.84(1.15-2.97)$ \\
\hline One visit or more ${ }^{a}$ & $7842(95.3)$ & $238(30.3)$ & 1.0 & 1.0 \\
\hline Birth attendant & 8230 & & & \\
\hline Physician $^{a}$ & $6(0.1)$ & $2(333.3)$ & 1.0 & \\
\hline Nurse/midwife & 1781 (21.6) & $76(42.7)$ & $0.09(0.00-7.14)$ & \\
\hline TBA/family/unattended & $6443(78.3)$ & $193(30.0)$ & $0.06(0.00-4.83)$ & \\
\hline Delivery location & 8230 & & & \\
\hline Home/other & $6105(74.2)$ & $178(29.2)$ & $0.66(0.34-1.26)$ & \\
\hline Clinic/hospital $^{\text {a }}$ & $2125(25.8)$ & $93(43.8)$ & 1.0 & \\
\hline \multicolumn{5}{|l|}{ Infant characteristics } \\
\hline Sex & 8213 & & & \\
\hline Male & $4260(51.9)$ & $161(37.8)$ & $1.37(0.73-2.58)$ & \\
\hline Female $^{a}$ & $3953(48.1)$ & $110(27.8)$ & 1.0 & \\
\hline Gestational age, wk & 8213 & & & \\
\hline$<37$ & $302(3.7)$ & $117(387.4)$ & $31.86(15.52-65.40)$ & $7.64(3.18-18.37)$ \\
\hline$>37^{\mathrm{a}}$ & $7911(96.3)$ & $154(19.5)$ & 1.0 & 1.0 \\
\hline Birth weight, $g$ & 8192 & & & \\
\hline 500-1499 & $124(1.5)$ & $66(532.3)$ & $67.92(24.62-187.36)$ & $9.10(2.95-28.07)$ \\
\hline
\end{tabular}




\begin{tabular}{lrrrr}
\hline Categories & Total deliveries (\% Total) & $\begin{array}{r}\text { Total number of stillbirths } \\
\text { (stillbirth rate) }\end{array}$ & $\begin{array}{r}\text { Odds ratio (95\% CI) } \\
\text { Odds ratio (95\% CI) }\end{array}$ \\
$1500-2499$ & $846(10.3)$ & $75(88.7)$ & $5.81(2.71-12.46)$ & $2.78(1.74-4.43)$ \\
2500 & $7222(88.2)$ & $119(16.5)$ & 1.0 & 1.0 \\
Multiple births & 8230 & & & \\
Yes & $293(3.6)$ & $16(54.6)$ & $1.74(0.46-6.57)$ \\
No & $7937(96.4)$ & $255(32.1)$ & 1.0 \\
\hline
\end{tabular}

Abbreviations: GEE, generalized estimation model. 
Table 5

Characteristics by maternal age and associated fresh versus macerated stillbirths

\begin{tabular}{lrrr}
\hline Categories & $\begin{array}{r}\text { Fresh stillbirths } \\
\mathbf{n = 2 1 4}(\boldsymbol{\%} \text { Total) }\end{array}$ & $\begin{array}{r}\text { Macerated stillbirths } \\
\mathbf{n = 5 7}(\boldsymbol{\%} \text { Total) }\end{array}$ & Relative risk (95\% CI) \\
Maternal age, y & & & \\
$<25$ & $100(46.7)$ & $37(64.9)$ & 1.0 \\
$25-35^{\text {a }}$ & $83(38.8)$ & $12(21.1)$ & $0.39(0.11-1.45)$ \\
$>35$ & $31(14.5)$ & $8(14.0)$ & $0.70(0.14-3.40)$ \\
\hline
\end{tabular}


Table 6

Characteristics by mother, perinatal care, neonates, and associated early neonatal deaths

\begin{tabular}{|c|c|c|c|c|}
\hline Categories & Live born births (\% Total) & $\begin{array}{l}\text { Total number of early } \\
\text { neonatal deaths (early } \\
\text { neonatal mortality rate) }\end{array}$ & Odds ratio $(95 \% \mathrm{CI})$ & $\begin{array}{r}\text { GEE Model } \\
\text { Odds ratio }(95 \% \mathrm{CI})\end{array}$ \\
\hline \multicolumn{5}{|l|}{ Maternal characteristics } \\
\hline Maternal age, y & 7959 & & & \\
\hline$<25$ & $3906(49.1)$ & $128(32.8)$ & 1.0 & \\
\hline $25-35^{\mathrm{a}}$ & $2907(36.5)$ & $87(30.0)$ & $0.91(0.58-1.43)$ & \\
\hline$>35$ & $1146(14.4)$ & $40(35.0)$ & $1.07(0.59-1.93)$ & \\
\hline Education status & 7959 & & & \\
\hline No formal education & $5067(63.7)$ & $179(35.4)$ & $1.36(0.87-2.12)$ & \\
\hline Any formal education a & $2892(36.3)$ & $76(26.3)$ & 1.0 & \\
\hline Presence of partner & 7,959 & & & \\
\hline Single & $81(1.0)$ & $7(86.4)$ & $2.90(0.81-10.45)$ & \\
\hline Married/cohabiting & $7878(99.0)$ & $248(31.5)$ & 1.0 & \\
\hline Number of pregnancies & 7959 & & & \\
\hline 0 & $1773(22.3)$ & $73(41.2)$ & $1.30(0.80-2.10)$ & \\
\hline $1-3^{\mathrm{a}}$ & $3905(49.1)$ & $125(32.1)$ & 1.0 & \\
\hline$>3$ & $2281(28.7)$ & $57(25.1)$ & $0.78(0.46-1.30)$ & \\
\hline Number of children & 7959 & & & \\
\hline 0 & $2251(28.3)$ & $100(44.5)$ & $1.52(0.98-2.35)$ & \\
\hline $1-3^{\mathrm{a}}$ & $4201(52.8)$ & $125(29.8)$ & 1.0 & \\
\hline$>3$ & $1507(18.9)$ & $30(20.0)$ & $0.66(0.34-1.28)$ & \\
\hline Prenatal care & 7959 & & & \\
\hline No prenatal care & $355(4.5)$ & $24(67.8)$ & $2.32(1.14-4.70)$ & $2.27(1.42-3.62)$ \\
\hline One visit or more ${ }^{a}$ & $7604(95.5)$ & $231(30.4)$ & 1.0 & 1.0 \\
\hline Birth attendant & 7959 & & & \\
\hline Physician/nurse/midwife & $1709(21.5)$ & $74(43.4)$ & 1.0 & \\
\hline TBA/family/unattended & $6250(78.5)$ & $181(29.0)$ & $0.66(0.42-1.03)$ & \\
\hline Delivery location & 7959 & & & \\
\hline Home/other & $5927(74.5)$ & $169(28.6)$ & $0.66(0.43-1.02)$ & \\
\hline Clinic/hospital ${ }^{\text {a }}$ & $2032(25.5)$ & $86(42.4)$ & 1.0 & \\
\hline \multicolumn{5}{|l|}{ Infant characteristics } \\
\hline Sex & 7942 & & & \\
\hline Male & 4099 (51.6) & $146(35.7)$ & $1.28(0.85-1.93)$ & \\
\hline Female $^{\text {a }}$ & $3843(48.4)$ & $108(28.1)$ & 1.0 & \\
\hline Gestational age, wk & 7,942 & & & \\
\hline$<37$ & $185(2.3)$ & $106(573.0)$ & $68.84(39.96-118.58)$ & $22.93(10.15-51.83)$ \\
\hline$>37^{\mathrm{a}}$ & 7757 (97.7) & $148(19.1)$ & 1.0 & 1.0 \\
\hline Birth weight, $g$ & 7932 & & & \\
\hline $500-1499$ & $58(0.7)$ & $44(758.6)$ & $182.50(65.58-507.85)$ & $13.37(4.55-39.29)$ \\
\hline $1500-2499$ & $771(9.7)$ & $86(111.7)$ & $7.30(4.57-11.67)$ & $2.76(1.37-5.57)$ \\
\hline
\end{tabular}




\begin{tabular}{|c|c|c|c|c|}
\hline Categories & Live born births (\% Total) & $\begin{array}{r}\text { Total number of early } \\
\text { neonatal deaths (early } \\
\text { neonatal mortality rate) }\end{array}$ & Odds ratio (95\% CI) & $\begin{array}{r}\text { GEE Model } \\
\text { Odds ratio }(95 \% \text { CI })\end{array}$ \\
\hline 22500 & $7103(89.5)$ & $120(16.9)$ & 1.0 & 1.0 \\
\hline Multiple births & 7959 & & & \\
\hline Yes & $277(3.5)$ & $36(130.0)$ & $5.08(2.76-9.36)$ & \\
\hline No & $7682(96.5)$ & $219(28.6)$ & 1.0 & \\
\hline
\end{tabular}

Abbreviations: GEE, generalized estimation model. 